\title{
Groundwater cable bacteria conserve energy by sulfur disproportionation
}

\author{
Hubert Müller ${ }^{1} \cdot$ Sviatlana Marozava $^{2} \cdot$ Alexander J. Probst $^{1} \cdot$ Rainer U. Meckenstock $^{1}$
}

Received: 3 July 2019 / Revised: 28 October 2019 / Accepted: 4 November 2019 / Published online: 14 November 2019

(c) The Author(s) 2019. This article is published with open access

\begin{abstract}
Cable bacteria of the family Desulfobulbaceae couple spatially separated sulfur oxidation and oxygen or nitrate reduction by long-distance electron transfer, which can constitute the dominant sulfur oxidation process in shallow sediments. However, it remains unknown how cells in the anoxic part of the centimeter-long filaments conserve energy. We found 16S rRNA gene sequences similar to groundwater cable bacteria in a 1-methylnaphthalene-degrading culture (1MN). Cultivation with elemental sulfur and thiosulfate with ferrihydrite or nitrate as electron acceptors resulted in a first cable bacteria enrichment culture dominated $>90 \%$ by $16 \mathrm{~S}$ rRNA sequences belonging to the Desulfobulbaceae. Desulfobulbaceae-specific fluorescence in situ hybridization (FISH) unveiled single cells and filaments of up to several hundred micrometers length to belong to the same species. The Desulfobulbaceae filaments also showed the distinctive cable bacteria morphology with their continuous ridge pattern as revealed by atomic force microscopy. The cable bacteria grew with nitrate as electron acceptor and elemental sulfur and thiosulfate as electron donor, but also by sulfur disproportionation when $\mathrm{Fe}(\mathrm{Cl})_{2}$ or $\mathrm{Fe}$ $(\mathrm{OH})_{3}$ were present as sulfide scavengers. Metabolic reconstruction based on the first nearly complete genome of groundwater cable bacteria revealed the potential for sulfur disproportionation and a chemo-litho-autotrophic metabolism. The presence of different types of hydrogenases in the genome suggests that they can utilize hydrogen as alternative electron donor. Our results imply that cable bacteria not only use sulfide oxidation coupled to oxygen or nitrate reduction by LDET for energy conservation, but sulfur disproportionation might constitute the energy metabolism for cells in large parts of the cable bacterial filaments.
\end{abstract}

\section{Introduction}

Cable bacteria are filamentous multicellular microorganisms belonging to the family Desulfobulbaceae [1]. They appear in redox gradients where the cells of one end of the filaments seemingly oxidize sulfide to sulfate [2]. The electrons from sulfide oxidation can be transported over several centimeters by long-distance electron transfer (LDET) to the sediment

Supplementary information The online version of this article (https:// doi.org/10.1038/s41396-019-0554-1) contains supplementary material, which is available to authorized users.

Rainer U. Meckenstock

rainer.meckenstock@uni-due.de

1 Biofilm Center, University of Duisburg-Essen, Universitätsstr. 5, 45141 Essen, Germany

2 Institute of Groundwater Ecology, Helmholtz Zentrum München, Ingolstädter Landstraße 1, 85764 Neuherberg, Germany surface where they are used for oxygen or nitrate reduction [3-5]. The electrons are transported via conductive fibers in the periplasm leading to the distinctive morphology of a continuous ridge pattern over the whole length of cable bacteria [6]. Since their first discovery in sediments from Aarhus Bay [1], cable bacteria were found in many other marine sediments all over the world [7] but also in a freshwater stream in Denmark [8] as well as in groundwater contaminated with hydrocarbons [9]. So far, no attempts to cultivate cable bacteria in pure culture or in a stable enrichment culture have been successful. Based on genome sequencing, the cable bacteria known so far belong to a monophyletic sister clade of the genus Desulfobulbus with two proposed genera Candidatus Electrothrix and Candidatus Electronema [10,11]. 16S rRNA gene sequences of groundwater cable bacteria formed a distinct phylogenetic clade with the closest cultivable relative Desulfurivibrio alkaliphilus [12]; a single-celled, rod-shaped alkaliphilic microorganism capable of sulfur disproportionation [12] and sulfide oxidation with nitrate as electron acceptor [13]. 
Surprisingly, we found 16S rRNA gene sequences of groundwater cable bacteria in the enrichment culture $1 \mathrm{MN}$ [14] that anaerobically degrades 1-methylnaphthalene or naphthalene with ferric iron as electron acceptor. This culture contains two dominant organisms affiliated to Thermoanaerobacteraceae and Desulfobulbaceae (Fig. 1b). The Thermoanaerobacteraceae were identified as the degraders of naphthalene by stable isotope probing experiments and the detection of putative genes encoding enzymes for naphthalene degradation [14]. The Desulfobulbaceae shared 16S rRNA gene identity of $>98 \%$ with previously published sequences of groundwater cable bacteria (Fig. 1a) [9].
Since iron reduction and naphthalene oxidation are in stark contrast to the environmental conditions where cable bacteria are usually found, the discovery of groundwater cable bacteria in this chemo-organo-heterotrophic culture raised the question for their metabolic role. Our hypothesis was that sulfur disproportionation plays a major role in energy conservation of cable bacteria. Therefore, we enriched the cable bacteria in the absence of an organic electron source with elemental sulfur and $\mathrm{Fe}(\mathrm{OH})_{3}$ as sulfide scavenger or terminal electron acceptor. After four consecutive transfers, we performed substrate-turnover experiments with culture $1 \mathrm{MN}$ where we simulated the conditions that cells of the cable
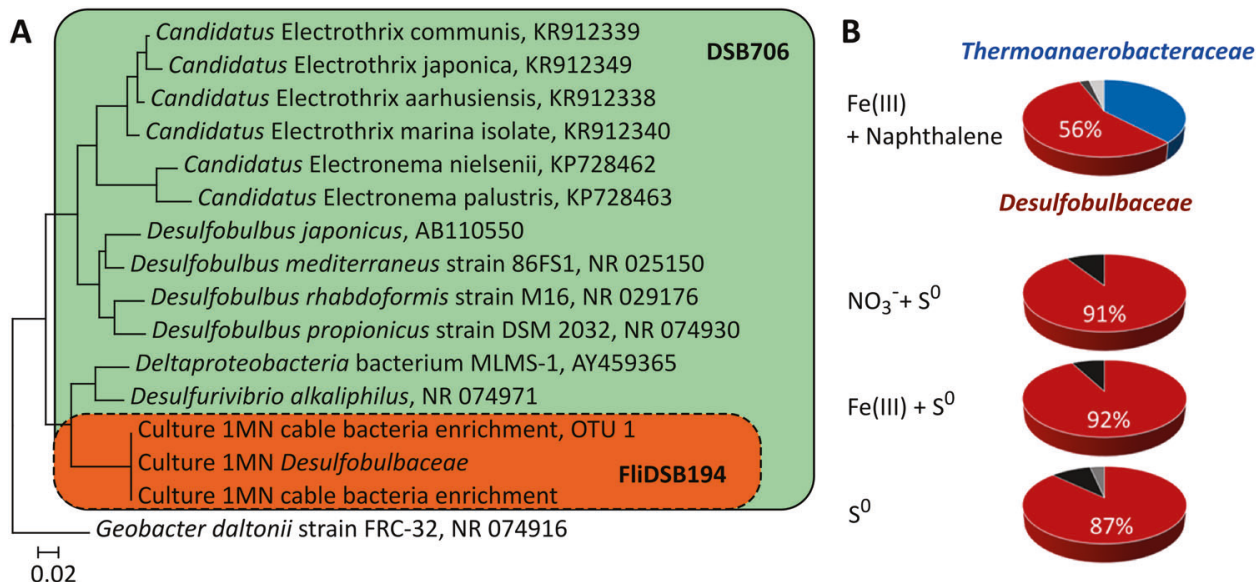

C

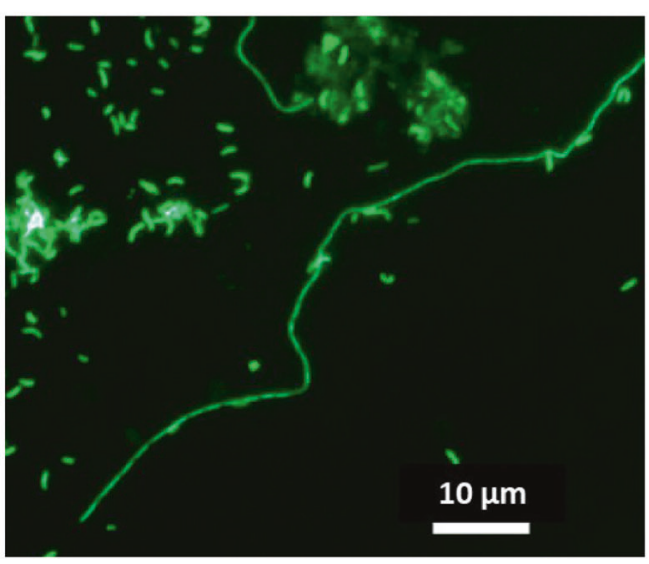

D

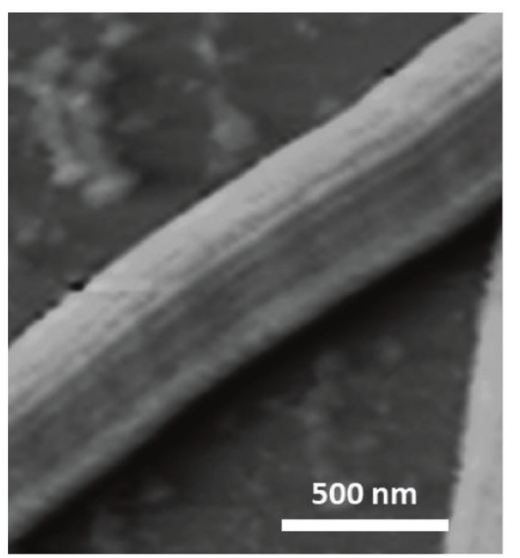

Fig. 1 Microbial composition in the obtained enrichment cultures. a Maximum likelihood phylogenetic tree of full-length 16S rRNA gene sequences of Desulfobulbaceae retrieved from the NCBI database in comparison to the cable bacteria (MAG Dsb_1MN) from culture $1 \mathrm{MN}$ (red frame). Partial sequences from amplicon sequencing (OTU 1) and sequences from the metagenomes of culture 1MN (MAG Dsb_1MN) and the cable bacteria enrichment showed $100 \%$ similarity. Scale bar represents the number of substitutions per site. Known cable bacteria are represented by full-length $16 \mathrm{~S}$ gene sequences of Candidatus Electrothrix and Candidatus Electronema. b Changes in microbial community composition of culture $1 \mathrm{MN}$ in the presence of different electron donor and acceptor combinations. The relative abundances of the MAG Dsb_1MN population and the Thermoanaerobacteraceae in the culture grown on 1-methylnaphthalene and ferrihydrite (top panel) were deduced from the average read coverage in the metagenome, which confirmed previous results obtained from fingerprinting by $\mathrm{T}$ RFLP (14). The relative abundances in the absence of 1methylnaphthalene were inferred from fingerprinting by T-RFLP and confirmed by amplicon sequencing (Fig. S6). c Fluorescence in situ hybridization (FISH) of the cable bacteria enrichment culture grown with elemental sulfur as electron donor and nitrate as electron acceptor stained with probe FliDSB194 specific for the MAG Dsb_1MN cable bacteria population. d Atomic force micrograph of filaments in culture $1 \mathrm{MN}$ grown with elemental sulfur and nitrate as electron acceptor showing the characteristic cell envelope of cable bacteria. The image displays the vertical deflection measured in contact mode 
bacteria filaments might be facing along the geochemical gradients by adding sulfide, elemental sulfur, or thiosulfate as electron sources. In addition, we performed genomeresolved metagenomics of the enrichment culture $1 \mathrm{MN}$ and our cable bacteria enrichment culture and generated the first available, near complete genome (MAG Dsb_1MN) (Table S2, Fig. S3) of a groundwater cable bacterium, of which we elucidated the genetic potential.

\section{Materials and methods}

\section{Cultivation of culture $1 \mathrm{MN}$}

The iron-reducing, 1-methylnaphtalene-degrading enrichment culture $1 \mathrm{MN}$ was enriched from a former coal gasification site in Gliwice, Poland [14]. It was grown in $125 \mathrm{ml}$ serum bottles filled with $65 \mathrm{ml}$ anoxic freshwater mineral medium [15] and sealed with butyl rubber stoppers under $80 \% \mathrm{~N}_{2}$ and $20 \% \mathrm{CO}_{2}$ (Linde, Germany) atmosphere. The medium was reduced with $0.7 \mathrm{mM} \mathrm{Na} \mathrm{Na}_{2} \mathrm{~S}$ and buffered to $\mathrm{pH} 7$ with $30 \mathrm{mM}$ carbonate buffer. Twenty millimolars amorphous ferrihydrite [16] served as sole electron acceptor and $0.35 \mathrm{mM} 1$-methylnaphthalene was added as electron donor and carbon source. Fresh cultures were started by inoculation with $10 \%$ from a previous culture and incubated at $30^{\circ} \mathrm{C}$.

\section{Substrate-turnover experiments}

To investigate if sulfur and iron cycles are coupled in culture $1 \mathrm{MN}$ and to elucidate the function of MAG Dsb_1MN, $2 \%(\mathrm{v} / \mathrm{v})$ of a $1 \mathrm{MN}$ culture grown with ferrihydrite and 1-methylnaphthalene were transferred to fresh medium reduced with $0.7 \mathrm{mM} \mathrm{Na} 2 \mathrm{~S}$ and amended with elemental sulfur or thiosulfate in the presence or absence of ferrihydrite or nitrate as electron acceptor (Table 1). In the presence of $\mathrm{Fe}(\mathrm{OH})_{3}$, the reducing agent $\mathrm{Na}_{2} \mathrm{~S}$ was abiotically oxidized to elemental sulfur or precipitated as black FeS. The media containing elemental sulfur were sterilized in an

Table 1 Incubation conditions for the substrate-turnover experiments with the cable bacteria enrichment culture

\begin{tabular}{llll}
\hline E-acceptor $^{\mathrm{a}}$ & E-donor $^{\mathrm{a}}$ & Reducing agent & $\mathrm{pH}$ \\
\hline $8 \mathrm{mM} \mathrm{NO}_{3}-$ & $3 \mathrm{mM} \mathrm{S}^{0}$ & $0.7 \mathrm{mM} \mathrm{Na}_{2} \mathrm{~S}$ & 6.4 \\
$8 \mathrm{mM} \mathrm{NO}_{3}-$ & $3 \mathrm{mM} \mathrm{S}_{2} \mathrm{O}_{3}{ }^{2-}$ & $0.7 \mathrm{mM} \mathrm{Na}_{2} \mathrm{~S}$ & 6.4 \\
$30 \mathrm{mM} \mathrm{Fe} \mathrm{OH})_{3}$ & $3 \mathrm{mM} \mathrm{S}^{0}$ & $0.7 \mathrm{mM} \mathrm{Na}_{2} \mathrm{~S}$ & 6.4 \\
$30 \mathrm{mM} \mathrm{Fe} \mathrm{OH})_{3}$ & $3 \mathrm{mM} \mathrm{S}_{2} \mathrm{O}_{3}{ }^{2-}$ & $0.7 \mathrm{mM} \mathrm{Na}_{2} \mathrm{~S}$ & 6.4 \\
$3 \mathrm{mM} \mathrm{S}^{0}$ & $10 \mathrm{mM} \mathrm{FeCl}_{2}$ & & 8.0 \\
$8 \mathrm{mM} \mathrm{S}_{2} \mathrm{O}_{3}{ }^{2-}$ & $10 \mathrm{mM} \mathrm{FeCl}_{2}$ & & 8.0 \\
\hline
\end{tabular}

${ }^{\mathrm{a}}$ In the absence of nitrate and $\mathrm{Fe}(\mathrm{OH})_{3}, \mathrm{~S}^{0}$ and $\mathrm{S}_{2} \mathrm{O}_{3}{ }^{2-}$ served as both electron donors and electron acceptors autoclave at $110^{\circ} \mathrm{C}$ for $30 \mathrm{~min}$ to prevent melting of the sulfur. No organic substrate was provided for growth and all experiments of this study were conducted after four consecutive transfers to exclude carryover of the methylnaphthalenes. Each of the different cultivations was performed in two replicates inoculated with $2 \%(\mathrm{v} / \mathrm{v})$ of the same source culture in order to start with the same microbial community composition and two abiotic controls.

\section{Analysis of the products of the substrate-turnover experiments}

Serum bottles were homogenized by manual shaking and $600 \mu \mathrm{l}$ of the culture were sampled with a syringe through the stopper. Samples were processed immediately for further analyses to minimize oxygen exposure. For iron measurements, $20 \mu \mathrm{l}$ sample were dissolved in $180 \mu \mathrm{l}$ of $1 \mathrm{M} \mathrm{HCl}$ for $\sim 3 \mathrm{~h}$. Fe(II) concentrations were determined with the ferrozine assay on a 96-well plate reader (Tecan, Switzerland) by measuring the absorbance at $560 \mathrm{~nm}[17,18]$. For sulfide analysis, $20 \mu \mathrm{l}$ of sample were fixed in $400 \mu \mathrm{l}$ of a $1 \%$ zinc acetate solution. Sulfide concentrations were measured within $2 \mathrm{~h}$ by the methylene blue method [19], which was downscaled to 96-well plate volumes [9]. To this end, $100 \mu \mathrm{l}$ of the sample trapped in zinc acetate were mixed directly in the 96-well plate with $100 \mu \mathrm{H}_{2} \mathrm{O}, 25 \mu \mathrm{l}$ 4-amino-N,Ndimethylaniline sulfate solution and oxidized to methylene blue with $25 \mu \mathrm{l}$ of ferric ammonium sulfate solution. The absorbance of triplicate samples was measured at $670 \mathrm{~nm}$ on a 96-well plate reader. Sulfide concentrations were calculated from a standard curve derived from different dilutions of a $100 \mathrm{mM} \mathrm{Na}_{2} \mathrm{~S}$ standard solution covering a range between $50 \mu \mathrm{M}$ and $5 \mathrm{mM}$. However, only dissolved sulfide and easily soluble $\mathrm{S}^{2-}$ were measured by this method. For measuring total acid-volatile sulfides (AVS), $100 \mu \mathrm{l}$ of sample were added to $7 \mathrm{ml}$ of $6 \mathrm{M} \mathrm{HCl}$ in a tube with anoxic headspace containing a sulfide trap of $400 \mu 10 \%$ (w/v) zinc acetate and incubated for $24 \mathrm{~h}$. The trapped sulfide was quantified as described above by the methylene blue method using a FeS standard for calibration. For ion chromatography, $100 \mu \mathrm{l}$ of sample were diluted in $900 \mu \mathrm{l}$ MilliQ water in an Eppendorf tube, immediately put on ice, and centrifuged for $15 \mathrm{~min}$ at $12,000 \mathrm{rpm}$ to remove iron particles and cells. Major anions $\left(\mathrm{NO}_{3}{ }^{-}, \mathrm{NO}_{2}{ }^{-}\right.$, and $\left.\mathrm{SO}_{4}{ }^{2-}\right)$ and cations $\left(\mathrm{NH}_{4}^{+}\right)$in the supernatant were measured by ion chromatography with a Dionex aquion system (Thermo Fisher Scientific, Dreieich, Germany).

\section{Atomic force microscopy}

For atomic force microscopy, $2 \mathrm{ml}$ of culture $1 \mathrm{MN}$ were fixed for at least $24 \mathrm{~h}$ in $2.5 \%$ glutaraldehyde at $4{ }^{\circ} \mathrm{C}$ and afterward centrifuged at $8000 \mathrm{rpm}$ for $20 \mathrm{~min}$. The 
supernatant was discarded and the pellet was resuspended in $200 \mu \mathrm{l} \mathrm{MilliQ}$ water. Twenty microliters of the cell suspension was dried for $2 \mathrm{~h}$ on a microscope glass slide and analyzed with an atomic force microscope (Nano Wizard, JPK Instruments, Germany) in contact mode using a CSC38/NO AL probe (Mikromasch, Tallinn, Estonia).

\section{DNA extraction, T-RFLP, and amplicon sequencing}

For DNA extraction, at least $10 \mathrm{ml}$ aliquots were centrifuged for $10 \mathrm{~min}$ at $18,000 \times g$ at $4{ }^{\circ} \mathrm{C}$. DNA was extracted from the pellet with a FastDNA Spin Kit for Soil (MP Biomedicals, Illkirch, France). 16S rRNA gene amplification and T-RFLP were performed as previously described using Ba27f (FAM-labeled) and 907r as primer for amplification and MSPI as restriction enzyme [20]. For amplicon sequencing, we used primers Pro341F and Pro805R [21] targeting 16S rRNA genes of prokaryotes. The first stage PCR was performed in KAPA HiFi Hot Start Ready Mix (Roche, Basel, Switzerland) by using $0.25 \mu \mathrm{M}$ of each forward and reverse primers ligated to Illumina overhang adapters (Eurofins Genomics, Ebersberg, Germany) and $1 \mu \mathrm{l}$ of extracted DNA as template in a total reaction volume of $25 \mu \mathrm{l}$. After an initial denaturation step at $94{ }^{\circ} \mathrm{C}$ for $5 \mathrm{~min}$, the PCR was performed in 30 cycles of denaturation at $94^{\circ} \mathrm{C}$ for $30 \mathrm{~s}$, annealing at $55^{\circ} \mathrm{C}$ for $30 \mathrm{~s}$, and extension at $70^{\circ} \mathrm{C}$ for $1 \mathrm{~min}$, and a final extension at $70{ }^{\circ} \mathrm{C}$ for $5 \mathrm{~min}$. The PCR amplicons were purified using MagSi-NGSPREP Plus magnetic beads (Steinbrenner, Wiesenbach, Germany) according to the Illumina $16 \mathrm{~S}$ metagenomic sequencing library preparation guide (part no. 15044223 Rev. B) with the modification that the beads were resuspended in $42.5 \mu \mathrm{l}$ of elution buffer EB (Qiagen, Hilden, Germany). Forty microliters of the supernatants were then taken for further analyses. The subsequent index PCR was performed using the Nextera XT DNA Library Preparation Kit v2 Set D (FC-131-2004) from Illumina (Munich, Germany) followed by a clean up according to the Illumina $16 \mathrm{~S}$ metagenomic sequencing library preparation guide. DNA concentrations were measured with a Qubit fluorometer (Thermo Fisher Scientific, Dreieich, Germany). The samples were normalized to a concentration of $4 \mathrm{ng} / \mu \mathrm{l}$ and $5 \mu \mathrm{l}$ of each sample were pooled in one ready-to-load sample, which was sequenced by GATC Biotech AG (Konstanz, Germany) on an Illumina Miseq platform. The demultiplexed raw reads of 250-bps length were processed using mothur by following the MySeq SOP [22, 23]. The quality-filtered and error-corrected sequences were clustered into operational taxonomic units (OTUs) at a defined cut-off level of $97 \%$ sequence similarity and classified by using the RDP classifier (mothur-formated trainset 16) [24]. Raw sequencing reads were deposited in the NCBI database in Bioproject ID PRJNA523091.

\section{Fluorescence in situ hybridization (FISH)}

Cells were fixed in $2.5 \%$ final concentration of a $25 \%$ anoxic glutaraldehyde solution and stored at $4{ }^{\circ} \mathrm{C}$ for later analysis. For FISH, fixed samples were centrifuged at $8000 \mathrm{rpm}$ for $30 \mathrm{~min}$ in an Eppendorf centrifuge, the supernatant was discarded, and the pellet was resuspended with MilliQ water in one fifth of the original volume. Twenty microliters of sample were transferred to wells of an eight-well microscope slide. The samples were dried at $46{ }^{\circ} \mathrm{C}$ for $2 \mathrm{~h}$ and dehydrated subsequently in 50,70 , and $98 \%$ ethanol for 3 min each. Hybridization and washing were done according to a previously published protocol [25] at a formamide concentration of $35 \%$. We used different oligonucleotide probes for the detection of cable bacteria: probe DSB706 (Cy3, double labeled; Biomers, Ulm, Germany) for Desulfobulbaceae [26] in general and probe FliDSB194 (6-FAM, double labeled; Biomers) [9] for groundwater cable bacteria in particular. Both probes match $100 \%$ with the $16 \mathrm{~S}$ rRNA gene sequence of the only OTU of Desulfobulbaceae present in the cable bacteria enrichments. Probe FliDSB194 was tested for its specificity in silico and is not expected to hybridize under the conditions used with $D$. alkaliphilus (two mismatches (MM)), D. propionicus (four MM), and $\mathrm{Ca}$. Electrothrix (six MM) and no 16S rRNA gene sequence of any of these bacteria has been detected by amplicon sequencing. As negative control, we used probe NON338 [27] (6-FAM, double labeled; Biomers) representing the complementary sequence to EUB338 [28], the general probe for bacteria. As additional negative control, we also applied probe CFX1223 (6-FAM, double labeled; Biomers) [29] targeting the Anaerolineaceae from the phylum Chloroflexi, which were also present in the cable bacteria enrichment cultures at minor relative abundance. Both probes showed no hybridization with the cable bacterial filaments (Fig. S7). After the washing step, cells were counterstained with $2 \mu \mathrm{g} \mathrm{\mu l}^{-1}$ 4' $^{\prime}$,6-diamidin-2phenylindol for $3 \mathrm{~min}$ and embedded in Citifluor AF1 (Citifluor, UK). Microscopy was performed with an eclipse epifluorescence microscope (Nikon, Melville, USA) using NiS elements software (version 4.10.01, Nikon) for imaging.

\section{Genome-resolved metagenomics}

We performed genome-resolved metagenomics on DNA extracted during a previously published SIP experiment of culture $1 \mathrm{MN}$ grown on naphthalene for 72 days [14]. Library preparation and 150-bps paired-end Illumina HiSeq sequencing were performed at GATC (Konstanz, Germany). Raw reads were trimmed and quality filtered with bbduk (http://jgi.doe.gov/data-and-tools/bbtools/) 
and SICKLE version 1.21 (https://github.com/najoshi/ sickle), and assembled and scaffolded with metaSPADES version 3.10.1 at default settings [30]. For scaffolds longer than $1 \mathrm{~kb}, 16 \mathrm{~S}$ rRNA genes were identified using CMsearch [31] and gene prediction was performed with prodigal in the meta mode (-p meta) [32]. The predicted genes were taxonomically and functionally annotated using diamond blastp [33] against the Uniref100 database [34]. The scaffolds were binned into draft bins using a tetranucleotide-frequency based emerging self-organizing map [35] and further curated using GC, taxonomy, and coverage information. The resulting bins were curated for scaffolding errors using ra2 [36] and again curated using GC, taxonomy, and coverage information. Quality of genomes was evaluated using 51 bacterial [37] and 38 archaeal single copy genes [38].

\section{Resequencing and strain analysis}

We used the $1 \mathrm{MN}$ culture as inoculum for enrichment cultures predicted to select for cable bacteria physiology. To confirm the target cable bacteria population (MAG Dsb_1MN) was present in the new enrichment cultures (lacking an organic carbon source) we sequenced the metagenomic DNA followed by read QC as described above. Using GC content, coverage, and taxonomy information, we also reconstructed a near complete genome of this dataset. To test the similarity between the genome enriched with sulfur and the one of the organism that was originally found in the $1 \mathrm{MN}$ culture we calculated the average nucleotide identity (http://enve-omics.ce.gatech. edu/ani/) between the two reconstructed genomes (window size 1000 bs, step size 200 bps, minimum length 700 bps, minimum identity $70 \%$, minimum alignments 50 ). In addition, we visualized the similarity between the two genomes using circoletto [39], based on blastn ( $e$-value cutoff 1-e-10). Then, we used stringent read mapping [40] and filtering for a maximum of three mismatches per read (equivalent to a sequencing error rate of $2 \%$ ). Newly generated reads were aligned to the reconstructed cable bacteria genome MAG Dsb_1MN. SNP, insertion and deletion were calculated using default settings in the Geneious software [41].

\section{Availability of metagenomic data}

Draft genome sequences were deposited in the NCBI database in Bioproject ID PRJNA475330 with the biosample accession numbers SAMN10188309, SAMN10188310, SAMN10188311, and SAMN10188512. The cable bacterial genome was uploaded to the Genoscope platform MAGE $[42,43]$ and annotated. Metabolic pathways were predicted by KEGG [44] pathway profiling of MAGE annotations.

\section{Phylogenetic analyses}

Phylogenetic trees of $16 \mathrm{~S}$ rRNA gene sequences were calculated in the MEGA X software [45] using the maximum likelihood method based on the Tamura-Nei model [46]. For phylogenetic placement of cable bacteria on the tree of life (beyond 16S rRNA gene analyses), we extracted 16 ribosomal proteins [47] using established methods [37]. The ribosomal proteins were aligned [48] with reference sequences of an in-house database consisting of 3800 dereplicated public genomes from previous publications [38, 47, 49]. Alignments were end-trimmed and manually inspected before concatenating them and building a tree using FastTree version 2.1.8 [50]. The resulting two-domain tree was pruned to a monophyletic subclade reflecting the position of the cable bacteria.

\section{Results}

After only four consecutive transfers of enrichment culture $1 \mathrm{MN}$ with sulfur as electron source, one of the original four OTUs was no longer detectable (Thermoanaerobacteraceae) and our target of putative cable bacteria was enriched to a relative amplicon abundance of $>90 \%$ (Fig. 1a, b, Fig. S6). Complementary FISH with probe FliDSB194 [9] specific for the cable bacterium and probe DSB706 [26] specific for the family Desulfobulbaceae (both matched $100 \%$ with the $16 \mathrm{~S}$ rRNA gene sequence of MAG Dsb_1MN) demonstrated that the cable bacterium was present in several hundred micrometer long filaments, but also in shorter filaments as well as in individual cells (Fig. 1c, Figs. S5, S7, and S8). The relative proportion of these cell forms in the cable bacteria enrichment culture changed over the course of the experiment (Fig. S7). The lengths of the filaments as well as the proportion of filaments over single cells seemed to increase with incubation time. All observed filaments were positive for probes FliDSB194 and DSB706 indicating that all cell forms belonged to the same cable bacteria represented by the genome sequence MAG Dsb_1MN (see below). Neither the filaments nor the single cells hybridized with probe NON338 as a negative control (Fig. S7). Atomic force microscopy revealed that all observed filaments showed the typical cell envelope with the continuous ridge pattern [1] confirming their morphology as cable bacteria (Fig. 1d). So far, we were not able to detect the ridge patterns for single cells of the cable bacteria.

When the cable bacteria enrichment culture was provided with elemental sulfur or thiosulfate as electron source and nitrate as electron acceptor, the culture showed production of sulfate with concomitant reduction of nitrate to ammonia (Fig. 2a, Fig. S1A, Table S1). However, the ammonium recovery was only $30-60 \%$ of the nitrate reduced (Table $\mathrm{S} 1$ ), 
Fig. 2 Development of concentrations of electron acceptor and sulfur species in the $1 \mathrm{MN}$ culture. Active cultures (filled symbols, solid lines) supplied with thiosulfate (left panel) or elemental sulfur (right panel) and electron acceptors a nitrate, b ferrihydrite, or $\mathbf{c}$ at disproportionation conditions in comparison to abiotic controls (open symbols, dashed lines). Concentrations of nitrate (circles), Fe(II) (squares), sulfate (triangles), and acid-volatile sulfides (AVS, diamonds) of one representative incubation is shown over the course of the experiment. Graphs of other replicate incubations are shown in Fig. S1
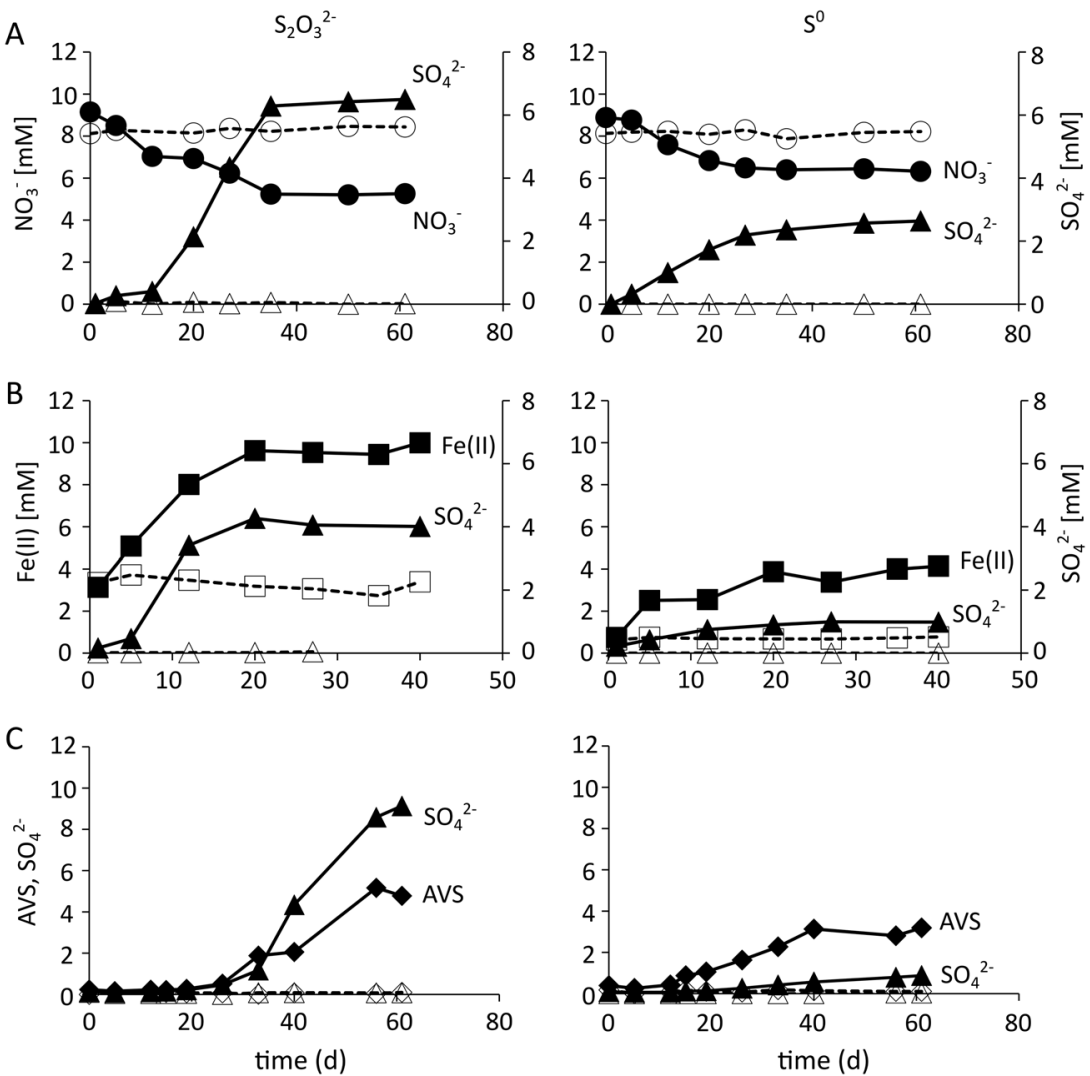

which might have been caused by degassing of ammonia from the medium. Since nitrite was only detected at low concentrations $(<100 \mu \mathrm{M})$, incomplete nitrate reduction to nitrite cannot explain this observation. Nevertheless, the decrease in nitrate fits to the stoichiometric oxidation of sulfur by dissimilatory nitrate reduction to ammonium (DNRA) (Fig. 2a, Fig. S1A, Table S1). This overall reaction might imply that the cable bacteria simply perform sulfur oxidation with nitrate as electron acceptor. Indeed, the genome of the cable bacteria (MAG Dsb_1MN) encodes for dissimilatory nitrate reduction to ammonia and a complete sulfate reduction pathway, which could have been operated in reverse (Fig. 3, Table S3). During days 5-12 of the incubation, one of the two replicate incubations with $\mathrm{S}_{2} \mathrm{O}_{3}{ }^{2-}$ as electron donor showed a high drop in $\mathrm{NO}_{3}{ }^{-}$concentration compared with a relatively low increase in $\mathrm{SO}_{4}{ }^{2-}$ concentrations. This was only observed once and might have been caused by issues during analysis of $\mathrm{SO}_{4}{ }^{2-}$ on day 12 . When we added ferric iron instead of nitrate as electron acceptor to cultures with sulfur or thiosulfate as substrate for sulfur disproportionation, again an oxidation of elemental sulfur to sulfate occurred coupled to the reduction of ferric iron. However, the stoichiometry and the production of AVS indicated an abiotic reduction of ferric iron with sulfide produced during disproportionation (Fig. 2b, Fig. S1B, Table S1). Indeed, we observed sulfur and thiosulfate disproportionation when free sulfide was kept very low by $\mathrm{Fe}$ (II) as a scavenger, indicated by a simultaneous increase of sulfate and AVS in a 1:3 or 1:1 ratio, respectively (Fig. 2c, Fig. S1C, Table S1). However, with longer incubation time less sulfide was measured than expected (Table S1), which might have been caused by: (a) degassing of sulfide, (b) electrons used for autotrophic carbon fixation, or (c) pyrite formation, which has been shown previously [51].

Sulfide can be toxic to cells but also thermodynamically inhibiting sulfur disproportionation. To test the effect of different sulfide concentrations on cable bacteria performing sulfide oxidation with nitrate as electron acceptor (as previously described for the closest cultivated relative Desulfurivibrio alkaliphilus [13]), we incubated our cable bacteria enrichment culture with nitrate as electron acceptor, elemental sulfur, or thiosulfate as electron donors, and different concentrations of sulfide from 0 to $2 \mathrm{mM}$ as potentially inhibiting sulfide background concentration. Sulfur oxidation or sulfur disproportionation did only take place at dissolved sulfide concentrations lower than $120 \mu \mathrm{M}$ and was completely inhibited at concentrations higher than $300 \mu \mathrm{M}$ at $\mathrm{pH} 6.4$ (Fig. S2).

To further elucidate the physiology of the cable bacteria (genome MAG Dsb_1MN), we investigated the metagenome of DNA extracted during the growth phase of culture $1 \mathrm{MN}$ on naphthalene after 72 days of incubation. We 


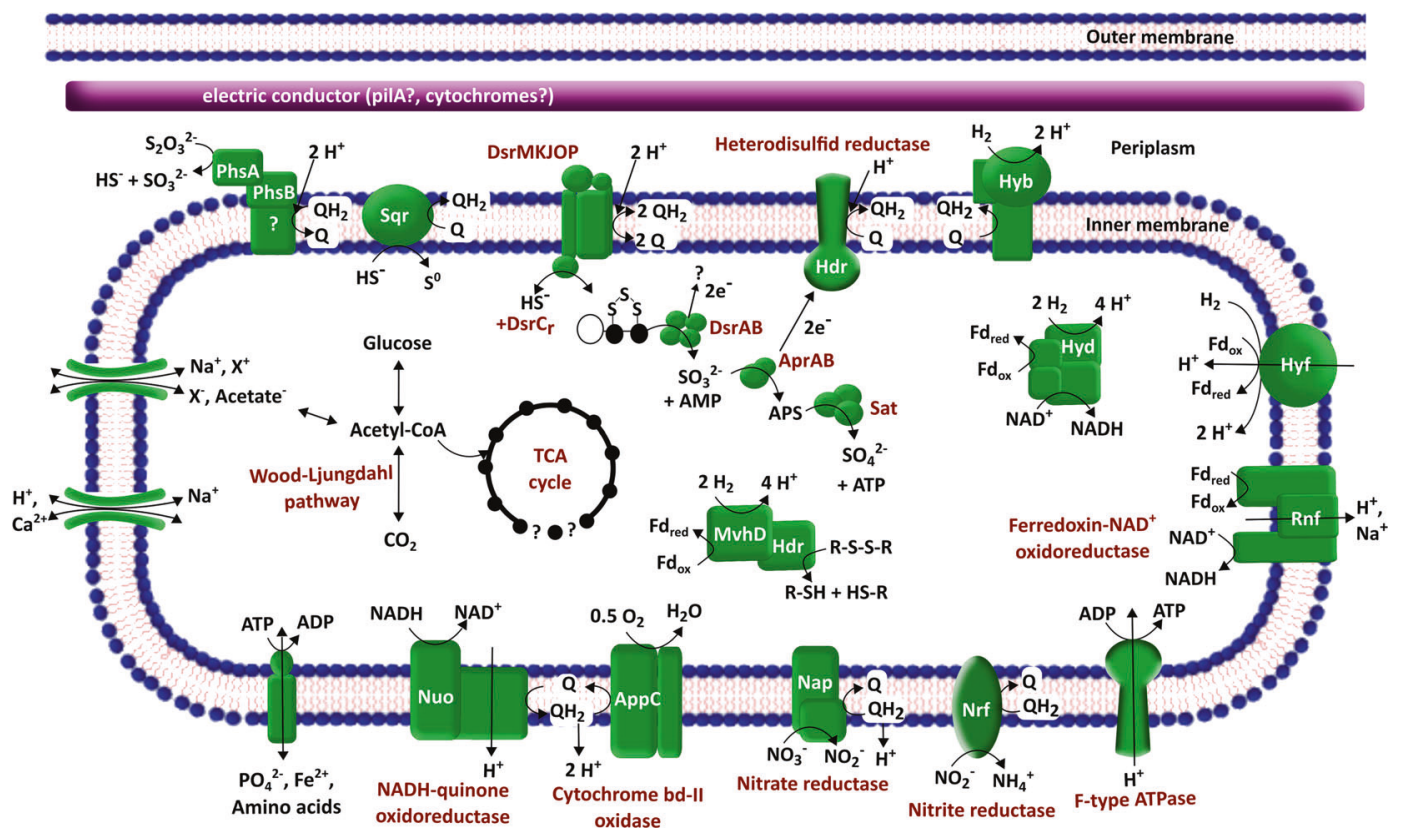

Fig. 3 Metabolic potential of groundwater cable bacteria (MAG Dsb_1MN). The pathways were inferred from KEGG [44] pathway profiling on the Genoscopes platform MAGE [42, 43]. The functions of enzymes involved in sulfur metabolism were inferred from the literature [13, 67]

received 6.7 million paired reads, which assembled into 141 scaffolds longer than 1 kbps. Binning of the scaffolds based on tetranucleotide frequencies led to four clearly separated genome bins, each belonging to a different phylum (Fig. S3). The genome MAG Dsb_1MN revealed hits for 2740 protein-coding genes against the Uniref100 database. Thirty-seven percent of these genes were coded for uncharacterized proteins. With an estimated genome completeness of $>98 \%$, MAG Dsb_1MN shows the so far highest completeness of all cable bacterial genomes [11]. We additionally sequenced the metagenome of our cable bacteria enrichment culture after substrate-turnover experiments and reconstructed a genome that has a $99.9 \%$ average nucleotide identity $(0.08 \% \mathrm{SD}$, two way) with the original genome. Whole genome alignments based on blast are provided in Fig. S9 and indicated that the recovered genomes are nearly identical (only a few SNPs were detected, Fig. S4). Within the community of the cable bacteria enrichment, we detected four different organisms based on ribosomal protein $\mathrm{S} 3$ (rpS3) markers. The cable bacterium was the dominant organism with a coverage of 447 for the rpS3-carrying scaffold (on average). A Chloroflexi sequence showed a coverage of 94 and the two other sequences (Actinobacteria and Verrucomicrobia) were both detected with 11-fold coverage per rpS3 scaffold. Hence, also the metagenomic data indicated that the cable bacteria (MAG Dsb_1MN) from culture 1MN were successfully enriched with sulfur as electron source.

Metabolic pathway prediction confirmed that the cable bacteria (genome MAG Dsb_1MN) have potential for versatile sulfur metabolism including all proteins of dissimilatory sulfate reduction, a sulfide-quinone reductase (SQR) and a thiosulfate reductase (PHS) (Fig. 3, Table S3). The genome codes for all proteins of DNRA confirming the results from our substrate-turnover experiments, which showed ammonium production with nitrate as electron acceptor (Tables S1 and S3). Genes for a terminal cytochrome bd-II oxidase indicate the potential of oxygen reduction (Fig. 3, Table S3). Intriguingly, the genome contains genes for four different types of hydrogenases suggesting hydrogen as alternative electron donor for cable bacteria. Specifically, electron bifurcating F420-non-reducing [52] and Hyd-type hydrogenases [53] in the cytoplasm might provide reduced ferredoxin and NADH for autotrophic $\mathrm{CO}_{2}$ fixation (Fig. 3, Table S3). Membrane bound Hyb- and Hyftype hydrogenases could couple hydrogen oxidation to quinone, $\mathrm{NAD}^{+}$, or ferredoxin reduction. Alternatively, the enzymes could produce hydrogen when operated in reverse. In addition, a ferredoxin-NAD ${ }^{+}$oxidoreductase (Rnf) complex could couple ferredoxin oxidation and $\mathrm{NAD}^{+}$reduction to energy conservation by dislocation of protons or sodium ions [54]. The proton motive force could be exploited for ATP generation by an F-type ATPase (Fig. 3, Table S3) [55].

Genes for the complete pathways of glycolysis/gluconeogenesis were present in the genome (Tables S1 and S3). The genome is lacking a complete TCA-cycle since we could not detect genes for fumarate reductase and succinate synthase (Fig. 3). Genome MAG Dsb_1MN shows potential for $\mathrm{CO}_{2}$ fixation reflected by the presence of all genes of a Wood-Ljungdahl pathway. So far, the composition of the 
conductive structures and the respective genes for a LDET are unknown. However, c-type cytochromes have been suggested to be involved in electron conduction and as a capacitor [5]. We found 15 genes coding for different c-type cytochromes of which, for instance, multiheme cytochromes DmsE and PpcG are known to be involved in periplasmatic electron transfer during iron reduction (Table S3) $[56,57]$. The genome encodes also for PilA, which might be involved in extracellular electron transport (Table S3) [58].

\section{Discussion}

In laboratory enrichment cultures as well as in contaminated aquifers, hydrocarbon-degrading organisms are frequently associated with highly abundant bacteria of the family Desulfobulbaceae closely related to groundwater cable bacteria $[9,14,59]$. We enriched groundwater cable bacteria originating from the iron-reducing, naphthalenedegrading culture $1 \mathrm{MN}$ to more than $90 \%$ in relative abundance, only with elemental sulfur as electron source and ferrihydrite as electron acceptor and sulfide scavenger. This supports the recent proposal that the Desulfobulbaceae might be involved in sulfur cycling during $1 \mathrm{MN}$ degradation in culture $1 \mathrm{MN}$ [14].

Specific FISH for groundwater cable bacteria revealed that the Desulfobulbaceae were present as several hundred $\mu \mathrm{m}$ long filaments, but also shorter filaments and single cells. This contrasts with findings for marine cable bacteria where to our knowledge no single-celled state was observed so far. Atomic force microscopy revealed the typical cable bacterial morphology with the continuous ridge pattern for our cable bacteria enrichment, similar to the originally discovered monophyletic cluster of cable bacteria $16 \mathrm{~S}$ rRNA sequences from marine and freshwater [10].

Since the discovery of cable bacteria, it has been a major question how the cells in the middle of the filaments conserve energy because there is no visible reaction taking place in the suboxic zone of the geochemical gradient. Obvious reactions are only the sulfide oxidation at the anodic end and oxygen reduction at the cathodic end of the filaments. In our substrate-turnover experiments with the cable bacteria enrichment culture we simulated the conditions that cells in the cable bacteria filament are facing along the geochemical gradients. The results presented here provide clear evidence that cable bacteria can conserve energy by sulfur or thiosulfate disproportionation with $\mathrm{FeCl}_{2}$ as sulfide scavenger (Fig. 2, Fig. S1). In this case, energy could be conserved in all cells via substrate-level phosphorylation in the last step of a reverse sulfate reduction pathway, when adenosinephosphosulfate is converted to sulfate and ATP by a reverse operating sulfate adenylyltransferase (Fig. 3, Table S3). We thus propose that the cable bacterial cells oxidize sulfide to elemental sulfur in a first step that is coupled by LDET to oxygen reduction or nitrate reduction to ammonium. The sulfur is then disproportionated by a reverse sulfate reduction pathway producing sulfate and sulfide. Hence, the role of LDET might be to provide elemental sulfur for the energy-conserving sulfur disproportionation. LDET thus mainly serves as an electron sink or acceptor for sulfide oxidation by cable bacteria but no energy can be conserved in this step. A similar mechanism has been demonstrated recently for Desulfurivibrio alkaliphilus [13]. Transcriptomics indicated that $D$. alkaliphilus oxidizes sulfide to elemental sulfur in a first step, which can then be either disproportionated or oxidized with nitrate as electron acceptor [13].

In contrast to D. alkaliphilus, our cable bacteria enrichment culture showed no sulfur disproportionation or oxidation of sulfide at concentrations higher than $300 \mu \mathrm{M}$ indicating a thermodynamic or toxic inhibition of sulfur disproportionation by free hydrogen sulfide. Since this inhibition is complete and inhibiting energy conservation, the cable bacteria can also not slowly oxidize the sulfide to lower concentrations where it could start off with growth. At the slightly acidic $\mathrm{pH}$ of 6.4 during our substrateturnover experiments with nitrate most of the sulfide was present as gaseous $\mathrm{H}_{2} \mathrm{~S}$, which can pass cell membranes [60] and consequently inhibit sulfur disproportionation. In contrast, at the alkaline $\mathrm{pH}$ during cultivation of $D$. alkaliphilus (>pH 9.5) almost all sulfide is present as $\mathrm{HS}^{-}$or $\mathrm{S}^{2-}$, which cannot pass the cell membranes. This might be the reason why $D$. alkaliphilus can grow at higher sulfide concentrations, whereas our cable bacteria cannot [13, 61].

Recently, three genomes of marine $\mathrm{Ca}$. Electrothrix and one genome of $\mathrm{Ca}$. Electronema have been published based on single-cell sequencing and metagenomics [11]. In the following, we provide an overview of the similarities and differences of these genomes to the genome MAG DSB_1MN of our cable bacteria. While the genome size of $3.1 \mathrm{Mbps}$ of MAG DSB_1MN is within the range of 2.7-4.0 Mbps reported for other cable bacteria, MAG DSB_1MN has a clearly higher GC content of 57\% compared with $\sim 50 \%$ already distinguishing MAG DSB_1MN from other cable bacteria. MAG DSB_1MN has several genes which might have been lost, reduced, or replaced in other cable bacteria such as the glycolytic enzyme enolase, a complete DsrKMJOP complex, and the NADH-quinone oxidoreductase (Nuo) enzyme complex (Table S3) [11]. Like in other cable bacteria and in D. alkaliphilus, an SQR might oxidize sulfide to elemental sulfur and the sulfate reduction pathway might be operated in reverse for energy conservation. No reverse-type dissimilatory sulfite reductase was observed, which is in accordance to other cable bacteria, D. alkaliphilus, and also other sulfur 
disproportionating Desulfobulbaceae such as D. propionicus. Kieldsen et al. [11] suggested energy conservation by sulfur disproportionation by a polysulfide reductase when cable bacteria are disconnected from electron acceptors. So far, we were not able to detect genes encoding for this enzyme in MAG DSB_1MN. One of the main questions since the discovery of cable bacteria is about the composition of the electron conductor. Based on metagenomic and proteomic data, Kieldsen et al. hypothesized electrically conductive type IV pili (e-pili) might form conductive superstructures in the periplasm. Our genomic data of MAG DSB_1MN also allow for this possibility, since we also found the gene coding for PilA in the genome. The amino acid sequence shows the same distribution of aromatic amino acids like electrically conductive e-pili (Fig. S10) [58].

Interestingly, genome analysis revealed genes for hydrogenases indicating the potential of MAG DSB_1MN to use hydrogen as alternative electron donor (Fig. 3, Table S3). Hydrogen might be an alternative electron source for cable bacteria in organic-rich habitats dominated by fermentation. However, this is in contrast to the genomes of marine and freshwater cable bacteria where a cytoplasmatic hydrogenase was detected only in $C a$. $E$. aarhusiensis and periplasmatic hydrogenases were absent [11]. The presence of a complete Wood-Ljungdahl pathway for $\mathrm{CO}_{2}$ fixation, which is in accordance to previously published genomes [11], and the absence of an organic C-source in our enrichment culture strongly indicates the capability of MAG DSB_1MN of a chemolitho-autotrophic metabolism.
Our cable bacteria enrichment culture was also capable of nitrate reduction to ammonium, which was confirmed by genes encoding for nitrate and nitrite reductases in genome MAG DSB_1MN. Although we did not test for oxygen as electron acceptor, genes encoding for cytochrome bd oxidase indicate that these organisms can reduce oxygen as terminal electron acceptor (Fig. 3, Table S3). Nevertheless, groundwater cable bacteria showed oxygen reduction in laboratory incubations of aquifer sediments [9]. Intriguingly, genes encoding for a cytochrome bd oxidase for oxygen as electron acceptor were absent in the genomes of $\mathrm{Ca}$. Electrothrix and $\mathrm{Ca}$. Electronema [11].

These results allow us to suggest a new model for energy conservation of cable bacteria, which provides an explanation of how each cell within the cable bacterial filament can conserve energy (Fig. 4). Near the surface, cable bacteria perform the cathodic reaction, i.e., the reduction of oxygen and nitrate to water and ammonium, respectively. So far, it is unclear if cable bacteria conserve energy from oxygen reduction. For instance, closely related species such as Desulfobulbus propionicus can reduce oxygen but show no growth with oxygen as electron acceptor [62]. We propose that below the cathodic zone elemental sulfur is disproportionated to sulfate and sulfide, whereas the sulfide is again oxidized to sulfur by LDET. The elemental sulfur can either be produced abiotically by fluctuating redox conditions or by a LDET by the cable bacteria themselves. Hence, the apparent overall reaction at the anodic part of the filaments is a net oxidation of sulfide to sulfate but energy is most likely conserved by sulfur disproportionation only. In natural sediments, chemo-organo-heterotrophic, sulfate-reducing bacteria

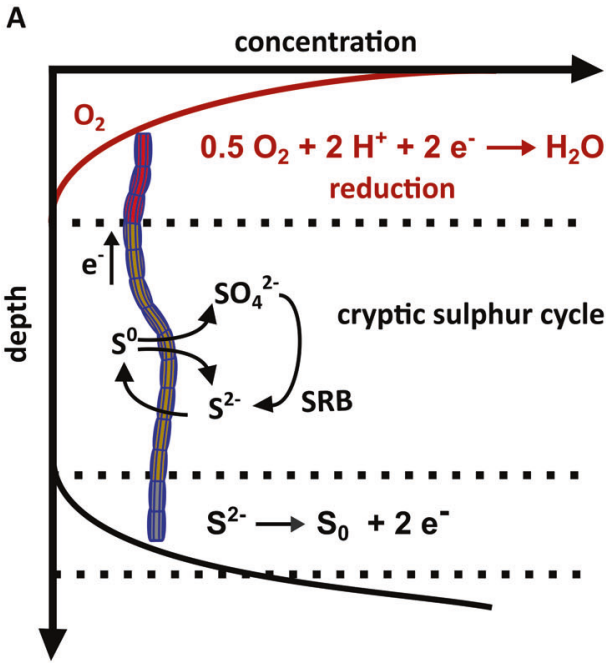

Fig. 4 Conceptual model for energy conservation in groundwater cable bacteria. a, b Filaments span the suboxic zone by a long-distance electron transfer. Within the suboxic zone and the anodic zone, sulfide is oxidized to elemental sulfur, which is then used to conserve energy by sulfur disproportionation via a reverse sulfate reduction pathway.
B

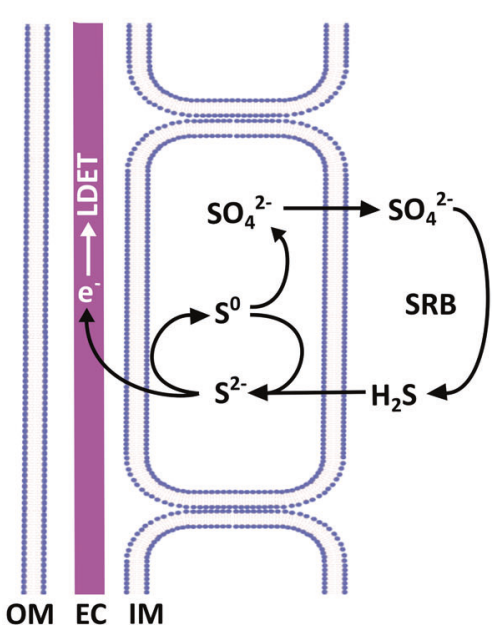

At the cathodic end, oxygen or nitrate reduction take place as electron accepting process for the LDET. Sulfide is provided all along the filament by sulfate-reducing bacteria. The sulfate is recycled by the cable bacteria providing a cryptic sulfur cycle in the suboxic zone. IM inner membrane; OM outer membrane; EC electric conductor 
will be abundant all along the cable bacteria filament and oxidize organic material with concomitant reduction of sulfate to sulfide (Fig. 4) [63]. We propose that all cells of the cable bacteria can oxidize this sulfide to elemental sulfur by LDET and the electrons are channeled through the cable filaments to the oxygen- or nitrate-reducing cathodic end. In fact, this pathway provides an explanation for energy conservation throughout the entire filament.

The energy-conserving sulfur disproportionation reaction requires low sulfide concentrations [64]. This suggests that in sediments the anodic oxidation of sulfide is limited to the suboxic zone and a narrow zone at the measurable end of the sulfide gradient (Fig. 4), which is characterized by low concentrations but high fluxes of sulfide. Hence, the functioning of cable bacteria relies on a delicate equilibrium between the rate of electron removal by LDET (and consequent oxygen or nitrate reduction rates) and the sulfide reduction rates by sulfate reducers (Fig. 4). Either a decrease of LDET, by, e.g., lower oxygen supply, or higher sulfate reduction rates could lead to increased sulfide concentrations along the filaments and immediate inactivation of the cable bacteria function. This might explain the frequently observed sudden disappearance of cable bacteria populations and LDET in marine sediments [65, 66].

Acknowledgements RUM and HM acknowledge funding from the European Research Council grant no. 666952-EcOILogy. We thank Vincent Scholz for technical assistance. AJP acknowledges funding by the Ministerium für Kultur und Wissenschaft des Landes NordrheinWestfalen (Nachwuchsgruppe Dr Alexander Probst).

Author contributions RUM acquired the funding. HM and RUM designed the strategy and experiments. HM and SM performed the laboratory work and analyses. HM and AJP performed genomeresolved metagenomics. HM wrote the manuscript with revisions from all authors.

\section{Compliance with ethical standards}

Conflict of interest The authors declare that they have no conflict of interest.

Publisher's note Springer Nature remains neutral with regard to jurisdictional claims in published maps and institutional affiliations.

Open Access This article is licensed under a Creative Commons Attribution 4.0 International License, which permits use, sharing, adaptation, distribution and reproduction in any medium or format, as long as you give appropriate credit to the original author(s) and the source, provide a link to the Creative Commons license, and indicate if changes were made. The images or other third party material in this article are included in the article's Creative Commons license, unless indicated otherwise in a credit line to the material. If material is not included in the article's Creative Commons license and your intended use is not permitted by statutory regulation or exceeds the permitted use, you will need to obtain permission directly from the copyright holder. To view a copy of this license, visit http://creativecommons. org/licenses/by/4.0/.

\section{References}

1. Pfeffer C, Larsen S, Song J, Dong M, Besenbacher F, Meyer RL, et al. Filamentous bacteria transport electrons over centimetre distances. Nature. 2012;491:218-21.

2. Nielsen LP, Risgaard-Petersen N. Rethinking sediment biogeochemistry after the discovery of electric currents. Ann Rev Mar Sci. 2015;7:425-42.

3. Nielsen LP, Risgaard-Petersen N, Fossing H, Christensen PB, Sayama M. Electric currents couple spatially separated biogeochemical processes in marine sediment. Nature. 2010;463:1071-4.

4. Marzocchi U, Trojan D, Larsen S, Meyer RL, Revsbech NP, Schramm A, et al. Electric coupling between distant nitrate reduction and sulfide oxidation in marine sediment. ISME J. 2014;8:1682-90.

5. Bjerg JT, Boschker HTS, Larsen S, Berry D, Schmid M, Millo D, et al. Long-distance electron transport in individual, living cable bacteria. Proc Natl Acad Sci USA. 2018;115:5786-91.

6. Meysman FJR, Cornelissen R, Trashin S, Bonne R, Martinez SH, van der Veen J, et al. A highly conductive fibre network enables centimetre-scale electron transport in multicellular cable bacteria. Nat Commun. 2019;10:4120.

7. Burdorf LDW, Tramper A, Seitaj D, Meire L, Hidalgo-Martinez $\mathrm{S}$, Zetsche EM, et al. Long-distance electron transport occurs globally in marine sediments. Biogeosciences. 2017;14: 683-701.

8. Risgaard-Petersen N, Kristiansen M, Frederiksen RB, Dittmer AL, Bjerg JT, Trojan D, et al. Cable bacteria in freshwater sediments. Appl Environ Microbiol. 2015;81:6003-11.

9. Müller H, Bosch J, Griebler C, Damgaard LR, Nielsen LP, Lueders $\mathrm{T}$, et al. Long-distance electron transfer by cable bacteria in aquifer sediments. ISME J. 2016;10:2010-9.

10. Trojan D, Schreiber L, Bjerg JT, Boggild A, Yang T, Kjeldsen $\mathrm{KU}$, et al. A taxonomic framework for cable bacteria and proposal of the candidate genera Electrothrix and Electronema. Syst Appl Microbiol. 2016;39:297-306.

11. Kjeldsen KU, Schreiber L, Thorup CA, Boesen T, Bjerg JT, Yang $\mathrm{T}$, et al. On the evolution and physiology of cable bacteria. Proc Natl Acad Sci USA. 2019;116:19116-25.

12. Sorokin DY, Tourova TP, Mussmann M, Muyzer G. Dethiobacter alkaliphilus gen. nov. sp. nov., and Desulfurivibrio alkaliphilus gen. nov. sp. nov.: two novel representatives of reductive sulfur cycle from soda lakes. Extremophiles. 2008;12:431-9.

13. Thorup C, Schramm A, Findlay AJ, Finster KW, Schreiber L. Disguised as a sulfate reducer: growth of the deltaproteobacterium Desulfurivibrio alkaliphilus by sulfide oxidation with nitrate. Mbio. 2017;8:e0671-17.

14. Marozava S, Mouttaki H, Müller H, Laban NA, Probst AJ, Meckenstock RU. Anaerobic degradation of 1-methylnaphthalene by a member of the Thermoanaerobacteraceae contained in an ironreducing enrichment culture. Biodegradation. 2018;29:23-39.

15. Widdel F, Bak F. Gram-negative mesophilic sulfate-reducing bacteria. In: The prokaryotes. New York, NY: Springer; 1992. p. 3352-78.

16. Lovley DR, Phillips EJ. Organic matter mineralization with reduction of ferric iron in anaerobic sediments. Appl Environ Microbiol. 1986;51:683-9.

17. Braunschweig J, Bosch J, Heister K, Kuebeck C, Meckenstock RU. Reevaluation of colorimetric iron determination methods commonly used in geomicrobiology. J Microbiol Methods. 2012;89:41-8.

18. Stookey LL. Ferrozine - a new spectrophotometric reagent for iron. Anal Chem. 1970;42:779.

19. Cline JD. Spectrophotometric determination of hydrogen sulfide in natural waters. Limnol Oceanogr. 1969;14:454. 
20. Pilloni G, von Netzer F, Engel M, Lueders T. Electron acceptordependent identification of key anaerobic toluene degraders at a tar-oil-contaminated aquifer by Pyro-SIP. FEMS Microbiol Ecol. 2011;78:165-75.

21. Takahashi S, Tomita J, Nishioka K, Hisada T, Nishijima M. Development of a prokaryotic universal primer for simultaneous analysis of bacteria and archaea using next-generation sequencing. PloS One. 2014;9:e105592.

22. Schloss PD, Westcott SL, Ryabin T, Hall JR, Hartmann M, Hollister EB, et al. Introducing mothur: open-source, platformindependent, community-supported software for describing and comparing microbial communities. Appl Environ Microbiol. 2009;75:7537-41.

23. Kozich JJ, Westcott SL, Baxter NT, Highlander SK, Schloss PD. Development of a dual-index sequencing strategy and curation pipeline for analyzing amplicon sequence data on the MiSeq Illumina sequencing platform. Appl Environ Microbiol. 2013;79:5112-20.

24. Wang Q, Garrity GM, Tiedje JM, Cole JR. Naive Bayesian classifier for rapid assignment of rRNA sequences into the new bacterial taxonomy. Appl Environ Microbiol. 2007;73:5261-7.

25. Pernthaler J, Glockner FO, Schonhuber W, Amann R. Fluorescence in situ hybridization (FISH) with rRNA-targeted oligonucleotide probes. Method Microbiol. 2001;30:207-26.

26. Loy A, Lehner A, Lee N, Adamczyk J, Meier H, Ernst J, et al. Oligonucleotide microarray for 16S rRNA gene-based detection of all recognized lineages of sulfate-reducing prokaryotes in the environment. Appl Environ Microbiol. 2002;68:5064-81.

27. Wallner G, Amann R, Beisker W. Optimizing fluorescent in situ hybridization with rRNA-targeted oligonucleotide probes for flow cytometric identification of microorganisms. Cytometry. 1993;14:136-43.

28. Amann RI, Binder BJ, Olson RJ, Chisholm SW, Devereux R, Stahl DA. Combination of 16S rRNA-targeted oligonucleotide probes with flow cytometry for analyzing mixed microbial populations. Appl Environ Microbiol. 1990;56:1919-25.

29. Björnsson L, Hugenholtz P, Tyson GW, Blackall LL. Filamentous Chloroflexi (green non-sulfur bacteria) are abundant in wastewater treatment processes with biological nutrient removalc. Microbiology. 2002;148:2309-18.

30. Nurk S, Meleshko D, Korobeynikov A, Pevzner PA. metaSPAdes: a new versatile metagenomic assembler. Genome Res. 2017;27:824-34.

31. Cui X, Lu Z, Wang S, Jing-Yan Wang J, Gao X. CMsearch: simultaneous exploration of protein sequence space and structure space improves not only protein homology detection but also protein structure prediction. Bioinformatics. 2016;32:i332-i40.

32. Hyatt D, Chen GL, Locascio PF, Land ML, Larimer FW, Hauser LJ. Prodigal: prokaryotic gene recognition and translation initiation site identification. BMC Bioinforma. 2010;11:119.

33. Buchfink B, Xie C, Huson DH. Fast and sensitive protein alignment using DIAMOND. Nat Methods. 2015;12:59-60.

34. Suzek BE, Wang Y, Huang $\mathrm{H}, \mathrm{McG}$ arvey $\mathrm{PB}, \mathrm{Wu} \mathrm{CH}$, UniProt C. UniRef clusters: a comprehensive and scalable alternative for improving sequence similarity searches. Bioinformatics. 2015;31:926-32.

35. Dick GJ, Andersson AF, Baker BJ, Simmons SL, Thomas BC, Yelton AP, et al. Community-wide analysis of microbial genome sequence signatures. Genome Biol. 2009;10:R85.

36. Brown CT, Hug LA, Thomas BC, Sharon I, Castelle CJ, Singh A, et al. Unusual biology across a group comprising more than $15 \%$ of domain Bacteria. Nature. 2015;523:208-U173.

37. Probst AJ, Castelle CJ, Singh A, Brown CT, Anantharaman K, Sharon I, et al. Genomic resolution of a cold subsurface aquifer community provides metabolic insights for novel microbes adapted to high CO2 concentrations. Environ Microbiol. 2017; 19:459-74

38. Probst AJ, Ladd B, Jarett JK, Geller-McGrath DE, Sieber CMK, Emerson JB, et al. Differential depth distribution of microbial function and putative symbionts through sediment- hosted aquifers in the deep terrestrial subsurface. Nat Microbiol. 2018;3:328-36.

39. Darzentas N. Circoletto: visualizing sequence similarity with Circos. Bioinformatics. 2010;26:2620-1.

40. Langmead B, Salzberg SL. Fast gapped-read alignment with Bowtie 2. Nat Methods. 2012;9:357-9.

41. Kearse M, Moir R, Wilson A, Stones-Havas S, Cheung M, Sturrock S, et al. Geneious Basic: an integrated and extendable desktop software platform for the organization and analysis of sequence data. Bioinformatics. 2012;28:1647-9.

42. Vallenet D, Calteau A, Cruveiller S, Gachet M, Lajus A, Josso A, et al. MicroScope in 2017: an expanding and evolving integrated resource for community expertise of microbial genomes. Nucleic Acids Res. 2017;45:D517-D28.

43. Vallenet D, Labarre L, Rouy Z, Barbe V, Bocs S, Cruveiller S, et al. MaGe: a microbial genome annotation system supported by synteny results. Nucleic Acids Res. 2006;34:53-65.

44. Kanehisa M, Sato Y, Kawashima M, Furumichi M, Tanabe M. KEGG as a reference resource for gene and protein annotation. Nucleic Acids Res. 2015;44:D457-D62.

45. Kumar S, Stecher G, Li M, Knyaz C, Tamura K. MEGA X: molecular evolutionary genetics analysis across computing platforms. Mol Biol Evol. 2018;35:1547-9.

46. Tamura K, Stecher G, Peterson D, Filipski A, Kumar S. MEGA6: molecular evolutionary genetics analysis version 6.0. Mol Biol Evol. 2013;30:2725-9.

47. Hug LA, Baker BJ, Anantharaman K, Brown CT, Probst AJ, Castelle CJ, et al. A new view of the tree of life. Nat Microbiol. 2016;1:16048.

48. Edgar RC. MUSCLE: multiple sequence alignment with high accuracy and high throughput. Nucleic Acids Res. 2004;32: 1792-7.

49. Anantharaman K, Brown CT, Hug LA, Sharon I, Castelle CJ, Probst AJ, et al. Thousands of microbial genomes shed light on interconnected biogeochemical processes in an aquifer system. Nat Commun. 2016;7:13219.

50. Price MN, Dehal PS, Arkin AP. FastTree 2-approximately maximum-likelihood trees for large alignments. PLoS One. 2010;5:e9490.

51. Thamdrup B, Finster K, Hansen JW, Bak F. Bacterial disproportionation of elemental sulfur coupled to chemical reduction of iron or manganese. Appl Environ Microbiol. 1993;59:101-8.

52. Greening C, Biswas A, Carere CR, Jackson CJ, Taylor MC, Stott $\mathrm{MB}$, et al. Genomic and metagenomic surveys of hydrogenase distribution indicate $\mathrm{H}-2$ is a widely utilised energy source for microbial growth and survival. ISME J. 2016;10:761-77.

53. Schuchmann K, Chowdhury NP, Muller V. Complex multimeric [FeFe] hydrogenases: biochemistry, physiology and new opportunities for the hydrogen economy. Front Microbiol. 2018;9:2911.

54. Buckel W, Thauer RK. Energy conservation via electron bifurcating ferredoxin reduction and proton/ $\mathrm{Na}(+)$ translocating ferredoxin oxidation. Geochim Cosmochim Acta. 2013;1827:94-113.

55. Buckel W, Thauer RK. Flavin-based electron bifurcation, ferredoxin, flavodoxin, and anaerobic respiration with protons (Ech) or $\mathrm{NAD}(+)(\mathrm{Rnf})$ as electron acceptors: a historical review. Front Microbiol. 2018;9:401.

56. Santos TC, Silva MA, Morgado L, Dantas JM, Salgueiro CA. Diving into the redox properties of Geobacter sulfurreducens cytochromes: a model for extracellular electron transfer. Dalton T. 2015;44:9335-44. 
57. Liu J, Chakraborty S, Hosseinzadeh P, Yu Y, Tian S, Petrik I, et al. Metalloproteins containing cytochrome, iron-sulfur, or copper redox centers. Chem Rev. 2014;114:4366-469.

58. Walker DJ, Adhikari RY, Holmes DE, Ward JE, Woodard TL, Nevin KP, et al. Electrically conductive pili from pilin genes of phylogenetically diverse microorganisms. ISME J. 2018;12: 48-58.

59. Kunapuli U, Lueders T, Meckenstock RU. The use of stable isotope probing to identify key iron-reducing microorganisms involved in anaerobic benzene degradation. ISME J. 2007; 1:643-53.

60. Mathai JC, Missner A, Kugler P, Saparov SM, Zeidel ML, Lee $\mathrm{JK}$, et al. No facilitator required for membrane transport of hydrogen sulfide. Proc Natl Acad Sci USA. 2009;106:16633-8.

61. Pellerin A, Antler G, Holm SA, Findlay AJ, Crockford PW, Turchyn AV, et al. Large sulfur isotope fractionation by bacterial sulfide oxidation. Sci Adv. 2019;5:eaaw1480.

62. Dannenberg S, Kroder M, Dilling W, Cypionka H. Oxidation of H-2, organic-compounds and inorganic sulfur-compounds coupled to reduction of $\mathrm{O}-2$ or nitrate by sulfate-reducing bacteria. Arch Microbiol. 1992;158:93-9.

63. Risgaard-Petersen N, Revil A, Meister P, Nielsen LP. Sulfur, iron, and calcium cycling associated with natural electric currents running through marine sediment. Geochim Cosmochim Acta. 2012;92:1-13.

64. Finster K. Microbiological disproportionation of inorganic sulfur compounds. J Sulfur Chem. 2008;29:281-92.

65. Rao AM, Malkin SY, Hidalgo-Martinez S, Meysman FJ. The impact of electrogenic sulfide oxidation on elemental cycling and solute fluxes in coastal sediment. Geochim Cosmochim Acta. 2015;172:265-86.

66. Seitaj D, Schauer R, Sulu-Gambari F, Hidalgo-Martinez S, Malkin SY, Burdorf LD, et al. Cable bacteria generate a firewall against euxinia in seasonally hypoxic basins. Proc Natl Acad Sci USA. 2015;112:13278-83.

67. Santos AA, Venceslau SS, Grein F, Leavitt WD, Dahl C, Johnston DT, et al. A protein trisulfide couples dissimilatory sulfate reduction to energy conservation. Science. 2015;350:1541-5. 